\title{
Comment arising from a paper by Wittmer et al.: hypothesis testing for top-down and bottom-up effects in woodland caribou population dynamics
}

Glen S. Brown • Lynn Landriault • Darren J. H. Sleep • Frank F. Mallory

Published online: 24 October 2007

(C) Springer-Verlag 2007

\section{Erratum to: Oecologia}

DOI 10.1007/s00442-007-0855-3

The original version of this article unfortunately contained a mistake. In the abstract, the source journal for the citation for Wittmer et al. (2005b) was incorrectly labelled as "(Can J Zool 83:407-418, 2005b)". The correct citation should be "(Oecologia 144:257-267, 2005b)".

The online version of the original article can be found under doi: 10.1007/s00442-007-0855-3.

\section{G. S. Brown ( $\square)$}

Ontario Terrestrial Assessment Program,

Ontario Ministry of Natural Resources,

1235 Queen Street East, Sault Ste. Marie,

ON, Canada P6A 2E5

e-mail: glen.brown@ontario.ca

L. Landriault

Wildlife Consultant, P.O. Box 521,

Dowling, ON, Canada P0M 1R0

\section{J. H. Sleep}

National Council for Air and Stream Improvement,

Station B, P.O. Box 1036, Montreal, PQ, Canada H3B 3K5

F. F. Mallory

Department of Biology, Laurentian University,

Sudbury, ON, Canada P3E 2C6 